\title{
Genetic determinism for within-litter birth weight variation and its relationship with litter weight and litter size in the Ripollesa ewe breed
}

\author{
J. Casellas ${ }^{\dagger}$, G. Caja and J. Piedrafita \\ Grup de Recerca en Remugants, Departament de Ciència Animal i dels Aliments, Universitat Autònoma de Barcelona, 08193 Bellaterra, Barcelona, Spain
}

(Received 11 December 2006; Accepted 1 March 2007)

\begin{abstract}
Birth weight plays a central role in lamb survival and growth, and the knowledge of its genetic determinism has become essential in worldwide selection programmes. Within this context, within-litter birth weight variation (BWV) has been suggested as an attractive trait to homogenise litters in prolific species, although it has not been analysed in sheep. The objective of this study was to ascertain whether maternal additive genetic variance exists for BWV in Ripollesa ewes, and to study its genetic, permanent environmental and residual relationships with litter weight (LW) and litter size (LS) at birth. Data were recorded in the Ripollesa experimental flock of the Universitat Autònoma of Barcelona, between 1986 and 2005, and included 1662 litters from 380 ewes, with 712 records of BWV and 1530 records of LW. Traits were analysed with a multivariate animal model solved through Bayesian methodologies, and with a threshold characterisation of LS. Additionally, the effect of BWV on lamb survival was studied. Additive genetic variance was observed for $B W V\left(\mathrm{~h}^{2}=0.061\right)$, as well as for $L W\left(\mathrm{~h}^{2}=0.200\right)$ and $L S\left(\mathrm{~h}^{2}=0.141\right)$. Nevertheless, genetic correlations among those traits were not substantial (BWV and $L W=0.151 ; B W V$ and $L S=-0.219 ; L W$ and $L S=-0.320$ ) and suffered from a high degree of uncertainly, with the null correlation included within the highest posterior interval at 95\%. Within-litter birth weight variation and $L S$ showed a negative and large permanent environmental correlation $(-0.872)$, and LW and LS were negatively correlated due to residual $(-0.762)$ and permanent environmental $(-0.449)$ random sources of variation. Within-litter birth weight variation influenced lamb mortality during the first 7 days of life $(\mathrm{P}<0.05)$, increasing and decreasing survivability in heavier and lighter littermates, respectively. Nevertheless, stillbirths and lambs died after the 1st week of life were not affected by BWV (P > 0.05). The low heritability found indicates that slow genetic progress may be expected from selecting for BWV. Close to zero genetic correlations suggest that this selection will probably not affect LS and LW, although some significant permanent and residual correlations must be taken into account. Further studies are needed to understand better the genetic architecture among these three reproductive traits.
\end{abstract}

Keywords: birth weight, genetic variation, litter size, litter weight, Ripollesa sheep

\section{Introduction}

Lamb birth weight has long been considered a major risk factor for lamb viability and survival (Gama et al., 1991; Christley et al., 2003), extreme birth weights being highly related to substantial increases in lamb mortality (Christley et al., 2003; Casellas et al., 2007c). Birth weight plays a central role in body temperature regulation with significant influences on lamb behaviour and metabolism (Dwyer and Morgan, 2006). Although genetic and environmental factors influencing birth weight have been widely analysed,

\footnotetext{
${ }^{\dagger}$ Present address: Genètica i Millora Animal, IRTA-Lleida, 25198 Lleida, Spain. E-mail: Joaquim.Casellas@irta.es
}

no studies have addressed the genetic aspects of within-litter birth weight variation (BWV) in lambs. Previous research in other prolific species like mice (Van Engelen et al., 1995), pigs (Högberg and Rydhmer, 2000; Damgaard et al., 2003) and rabbits (Garreau et al., 2004) suggested that selection for survivability could reduce BWV (Knol, 2001; Garreau et al., 2004). Within this context, lamb within-litter birth weight variation could become an appealing future survival criterion for sheep selection programmes in which litter size at birth (LS) is a main objective, although the genetic knowledge about this trait is very limited in sheep.

Litter size and litter weight (LW) at birth are two of the most important productive traits in meat sheep 
(Olesen et al., 1994; Freetly and Leymaster, 2004) and selection programmes are commonly focused on LS (Bhuiyan and Curran, 1993; Casellas et al., 2007b). Nevertheless, little is known about correlated effects on LW and BWV. Positive genetic and residual correlations have been suggested between LS and BWV in pigs (Damgaard et al., 2003) but we lack comparable results in sheep. The objective of this study was to ascertain whether additive genetic variance exists for within-litter BWV in lamb weight at birth. Further objectives were to estimate genetic, permanent environmental and residual correlations between BWV, LW and LS in sheep, as well as the relation between BWV and lamb survival.

\section{Material and methods}

\section{Ripollesa breed}

The Ripollesa is a medium-sized sheep (ewes, 50 to $65 \mathrm{~kg}$ live weight; rams, 75 to $90 \mathrm{~kg}$ live weight) and the most abundant native ovine breed in Catalonia, the north-east region of Spain (Guillaumet and Caja, 2001; Milán et al., 2003). Although with an unclear origin, this breed seems to derive from the crossbreeding of transhumant Merino individuals and the native ovine population of the Pyrenees Mountains (Torre, 1991), and has been related with the Spanish 'entrefino' trunk (Sánchez Belda and Sánchez Trujillano, 1986). Purebred animals are white with dark brown or black marks on the head and legs and with white wool and closed fleece (fibre diameter, 23 to $26 \mu \mathrm{m})$. The Ripollesa sheep is exploited under semi-intensive Mediterranean conditions for the production of 'Pascual-type' lambs (22 to $24 \mathrm{~kg}$ live weight at slaughter; Guillaumet and Caja, 2001) with an average mortality until slaughter of approximately 10\% (Casellas et al., 2007c). Ripollesa breed is usually considered as a low prolific breed (1.2 lambs per birth; Sánchez Belda and Sánchez Trujillano, 1986, Guillaumet and Caja, 2001) although recent studies have reported higher LS averages in genetically improved flocks (1.7 lambs per birth; Casellas et al., 2007b). The Ripollesa National Breeders Association (Associació Nacional de Criadors d'Ovins de Raça Ripollesa; ANCRI) was founded in year 1987 and focused the selection programme of the Ripollesa breed on litter size (Casellas et al., 2007b). At this time, the Ripollesa herdbook includes 4166 purebred ewes in 12 flocks, with a size ranged between 100 and 800 ewes. The current census remains unknown although it is assumed smaller than 50000 ewes, and with a variable incidence of crossbred individuals (R. Bach, personal communication).

\section{Field data collection and traits analysed}

Data were collected from a flock of Ripollesa purebred ewes kept at the experimental farm of the Universitat Autònoma of Barcelona (Bellaterra, Spain) since 1986. This flock was founded from the acquisition of ewes and rams from three purebred Ripollesa farms. Flock size varied between 80 and 120 ewes that lambed once per year and followed an autumn-lambing system, with the exception of replacement ewe-lambs that lambed in December-January since year 1995. See Casellas et al. (2007a and b) for a detailed description of the management system. Reproductive records were recorded from 1986 to the present. Lambs were ear-tagged at birth and sire, dam, date of birth, birth type (single, twin, triplet or quadruplet) and birth weight were recorded.

After editing, records were available on 1662 single $(55 \%)$ and twin $(45 \%)$ deliveries of 380 different ewes, 312 of them having repeated records. Note that triplet (31) and quadruplet (1) deliveries were exceptional and they were removed from the data set. Moreover, it allows for a straightforward definition of BWV and an easy conversion to absolute birth weight differences (see below). The pedigree for these ewes included a total of 21 sires and 411 dams, with all female and most male (92\%) ancestors known for animals born within the analysed flock. Three ewe reproductive traits were considered, BWV, LW and LS. Within-litter birth weight variation was defined for twin births as the s.d. between the birth weights of littermates following Damgaard et al. (2003). Given the exclusion of triplet and quadruplet deliveries from the analysis, the s.d. values can be easily converted into terms of absolute birth weight differences (BWD) with the formula BWD = $\mathrm{BWV} / \sqrt{2}$. Litter weight was defined as the sum of the birth weights of the lambs born, and LS took the value of the total number of lambs born (sum of alive and dead). Descriptive statistics for these variables are presented in Table 1 . Note that all these traits were defined as ewerelated traits.

\section{Models and statistical analysis}

A multivariate animal model was used in the joint analysis of BWV, LW and LS, with a linear approach for BWV and LW, and a threshold approach (Wright, 1934) for LS. Previous analysis showed that threshold models were preferable for LS in the Ripollesa breed (Casellas et al., 2007a). The assumed operational models included the additive genetic effect of each ewe $\left(a_{i}\right)$, the random permanent environmental effect of the ewe $\left(p_{i}\right)$ and three systematic sources of variation as follows:

$$
\begin{aligned}
B W V_{i j k l m} & =a_{i}+p_{i}+A E_{j}+Y R_{k}+B T S_{I}+e_{i j k l m} \\
L W_{i j k l m} & =a_{i}+p_{i}+A E_{j}+Y R_{k}+B T S_{I}+e_{i j k l m} \\
L S_{i j k m} & =a_{i}+p_{i}+A E_{j}+Y R_{k}+e_{i j k m}
\end{aligned}
$$

where $B W V_{i j k l m}, L W_{i j k l m}$ and $L S_{i j k m}$ were the mth phenotypic record for BWV, LW and $L S$, respectively, $A E_{j}$ was the age of the ewe at lambing $(<3,3$ to 5 , and $>5$ years), following the categories assumed by Casellas et al. (2007a and b), $Y R_{k}$ was the year of lambing with 20 levels from 1986 to 2005, and BTS, was the birth type-sex of lambs effect with five categories: (1) single birth and male lamb, (2) single birth and female lamb, (3) twin birth and two 
Table 1 Number of observations and means \pm s.e. for each class of each factor and trait

\begin{tabular}{|c|c|c|c|c|c|c|}
\hline & \multicolumn{2}{|c|}{$\begin{array}{c}\text { Within-litter birth weight } \\
\text { variation }(\mathrm{kg})\end{array}$} & \multicolumn{2}{|c|}{$\begin{array}{l}\text { Litter weight } \\
\quad(\mathrm{kg})\end{array}$} & \multicolumn{2}{|c|}{$\begin{array}{l}\text { Litter size, lambs } \\
\text { per birth }\end{array}$} \\
\hline & $n$ & Mean \pm s.e. & $n$ & Mean \pm s.e. & $n$ & Mean \pm s.e. \\
\hline \multicolumn{7}{|l|}{ Ewe age (years) } \\
\hline$<3$ & 110 & $0.30 \pm 0.02$ & 387 & $4.03 \pm 0.06$ & 414 & $1.27 \pm 0.02$ \\
\hline 3 to 5 & 312 & $0.31 \pm 0.01$ & 599 & $5.06 \pm 0.06$ & 651 & $1.51 \pm 0.02$ \\
\hline$>5$ & 290 & $0.33 \pm 0.01$ & 544 & $5.30 \pm 0.07$ & 597 & $1.52 \pm 0.02$ \\
\hline \multicolumn{7}{|l|}{ Year of lambing } \\
\hline 1986 & 15 & $0.38 \pm 0.12$ & 41 & $4.71 \pm 0.25$ & 103 & $1.38 \pm 0.05$ \\
\hline 1987 & 9 & $0.22 \pm 0.07$ & 31 & $4.91 \pm 0.22$ & 85 & $1.39 \pm 0.05$ \\
\hline 1988 & 35 & $0.33 \pm 0.05$ & 73 & $4.87 \pm 0.18$ & 79 & $1.47 \pm 0.06$ \\
\hline 1989 & 11 & $0.28 \pm 0.04$ & 46 & $4.50 \pm 0.17$ & 46 & $1.24 \pm 0.06$ \\
\hline 1990 & 28 & $0.24 \pm 0.05$ & 64 & $5.16 \pm 0.21$ & 64 & $1.44 \pm 0.06$ \\
\hline 1991 & 33 & $0.36 \pm 0.05$ & 79 & $4.28 \pm 0.16$ & 79 & $1.41 \pm 0.05$ \\
\hline 1992 & 45 & $0.29 \pm 0.04$ & 85 & $5.27 \pm 0.18$ & 88 & $1.51 \pm 0.05$ \\
\hline 1993 & 35 & $0.37 \pm 0.04$ & 108 & $4.61 \pm 0.16$ & 110 & $1.32 \pm 0.05$ \\
\hline 1994 & 30 & $0.25 \pm 0.03$ & 93 & $4.41 \pm 0.13$ & 93 & $1.32 \pm 0.05$ \\
\hline 1995 & 41 & $0.32 \pm 0.04$ & 82 & $5.31 \pm 0.17$ & 82 & $1.50 \pm 0.06$ \\
\hline 1996 & 30 & $0.33 \pm 0.06$ & 74 & $4.67 \pm 0.16$ & 77 & $1.41 \pm 0.06$ \\
\hline 1997 & 23 & $0.31 \pm 0.05$ & 73 & $4.73 \pm 0.17$ & 73 & $1.32 \pm 0.05$ \\
\hline 1998 & 38 & $0.35 \pm 0.04$ & 84 & $4.68 \pm 0.16$ & 85 & $1.45 \pm 0.05$ \\
\hline 1999 & 50 & $0.30 \pm 0.03$ & 83 & $5.27 \pm 0.15$ & 83 & $1.60 \pm 0.05$ \\
\hline 2000 & 57 & $0.35 \pm 0.03$ & 85 & $5.72 \pm 0.16$ & 86 & $1.66 \pm 0.05$ \\
\hline 2001 & 52 & $0.32 \pm 0.03$ & 89 & $4.93 \pm 0.17$ & 89 & $1.58 \pm 0.05$ \\
\hline 2002 & 42 & $0.29 \pm 0.04$ & 89 & $5.00 \pm 0.16$ & 89 & $1.47 \pm 0.05$ \\
\hline 2003 & 42 & $0.33 \pm 0.04$ & 78 & $4.67 \pm 0.19$ & 78 & $1.54 \pm 0.06$ \\
\hline 2004 & 43 & $0.25 \pm 0.04$ & 86 & $4.85 \pm 0.15$ & 86 & $1.50 \pm 0.05$ \\
\hline 2005 & 53 & $0.30 \pm 0.04$ & 87 & $5.01 \pm 0.18$ & 87 & $1.61 \pm 0.05$ \\
\hline \multicolumn{7}{|l|}{ Birth type/sex } \\
\hline Single, $\sigma^{7}$ & & & 414 & $3.92 \pm 0.04$ & & \\
\hline Single, $q$ & & & 404 & $3.67 \pm 0.04$ & & \\
\hline Twins, O & 183 & $0.31 \pm 0.02$ & 183 & $6.28 \pm 0.08$ & & \\
\hline Twins, $0^{\nearrow} q$ & 355 & $0.33 \pm 0.01$ & 355 & $6.14 \pm 0.06$ & & \\
\hline Twins, $+q$ 운 & 174 & $0.29 \pm 0.02$ & 174 & $6.00 \pm 0.09$ & & \\
\hline Overall & 712 & $0.31 \pm 0.01$ & 1530 & $4.89 \pm 0.04$ & 1662 & $1.45 \pm 0.01$ \\
\hline
\end{tabular}

male lambs, (4) twin birth and one male and one female lambs, and (5) twin birth and two female lambs. The last term, $e_{i j k l m}$ is the corresponding residual term.

Although data normality is not a mandatory attribute in mixed model equations, it is precisely when normality holds that mixed model equations can be viewed as an approximation to the best predictor (Henderson, 1973; Gianola and Fernando, 1986). Within this context, normality of BWV and LW was tested on the modal estimation of their residuals (see the Bayesian approach to the multivariate animal model described below) with the Wilk-Shapiro test (Shapiro and Wilk, 1965) implemented in the Univariate procedure of SAS (v.8.2, Statistical Analysis Systems Institute Inc., Cary, NC). A threshold model was assumed for LS (Wright, 1934) and therefore, normality was implicitly assumed on the underlying liability scale.

A multivariate linear-threshold model was implemented following the Bayesian methodologies described by Van Tassell et al. (1998). Litter size is a typical example of a productive trait with discrete phenotypic expression. Historically, difficulties with the statistical analysis of categorical traits have led to implementation of approximate methods with controversial results, negative heritabilities included (Fogarty, 1995), whereas this problem has a conceptually simple solution within the Bayesian framework (Sorensen et al., 1995; Van Tassell et al., 1998). In addition, data sets for the estimations of variance components of ovine reproductive traits often come from flocks under genetic selection on those traits, which was the case with our data set (Casellas et al., 2007b). Frequentist approaches typically ignore this peculiarity, allowing for biased estimates (Wang et al., 1994). From a Bayesian point of view, all of the information is contained in the joint posterior distribution, and a full Bayesian inference is possible (Wang et al., 1994), although the joint posterior, or any marginal posterior distribution becomes the same with or without selection (Sorensen et al., 1994). Within this context, the vectors of BWV ( $\left.\mathrm{y}_{\mathrm{BWV}}\right)$ and LW ( $\left.\mathrm{y}_{\mathrm{LW}}\right)$ 
phenotypic records sorted by ewe and LS liabilities ( $\mathbf{u}_{\mathrm{L}}$; Wright, 1934) were assumed to be sampled from the following multivariate normal distribution:

$$
\begin{aligned}
& p\left(\left[\begin{array}{c}
\mathbf{y}_{\mathrm{BWV}} \\
\mathbf{y}_{\mathrm{LW}} \\
\mathbf{u}_{\mathrm{LS}}
\end{array}\right] \mathbf{l}, \mathbf{p}, \mathbf{a}, \mathbf{R}\right) \sim \\
& \operatorname{MVN}\left(\left[\begin{array}{c}
\mathbf{X} \mathbf{b}_{\mathrm{BWV}}+\mathbf{Z}_{1} \mathbf{p}_{\mathrm{BWV}}+\mathbf{Z}_{2} \mathbf{a}_{\mathrm{BWV}} \\
\mathbf{X b}_{\mathrm{LW}}+\mathbf{Z}_{1} \mathbf{p}_{\mathrm{LW}}+\mathbf{Z}_{2} \mathbf{a}_{\mathrm{LW}} \\
\mathbf{X}_{\mathrm{LS}}+\mathbf{Z}_{1} \mathbf{p}_{\mathrm{LS}}+\mathbf{Z}_{2} \mathbf{a}_{\mathrm{LS}}
\end{array}\right], \mathrm{I} \otimes \mathbf{R}\right)
\end{aligned}
$$

where, $\mathbf{X}, \mathbf{Z}_{1}$ and $\mathbf{Z}_{2}$ were the corresponding incidence matrices of systematic $\left(\mathbf{b}^{\prime}=\left[\mathbf{b}_{\mathrm{BWV}}^{\prime} \mathbf{b}_{\mathrm{LW}}^{\prime} \mathbf{b}_{\mathrm{LS}}^{\prime}\right]\right)$, permanent environmental $\left(\boldsymbol{p}^{\prime}=\left[\boldsymbol{p}_{\mathrm{BWV}}^{\prime} \mathbf{p}_{\mathrm{LW}}^{\prime} \boldsymbol{p}_{\mathrm{LS}}^{\prime}\right]\right)$, and additive genetic $\left(\mathbf{a}^{\prime}=\left[\mathrm{a}_{\mathrm{BWV}}^{\prime} \mathbf{a}_{\mathrm{LW}}^{\prime} \mathbf{a}_{\mathrm{LS}}^{\prime}\right]\right)$ effects, respectively. Note that $\mathbf{R}$ was the residual (co)variance matrix with dimensions $3 \times 3$, and I was the corresponding identity matrix. The response of $L S$ ( $\mathrm{y}_{\mathrm{LS}}$ ) was modeled with the following distribution:

$$
\begin{aligned}
p\left(\mathbf{y}_{\mathrm{LS}} \mid \mathbf{u}_{\mathrm{LS}}\right)= & \prod_{i=1}^{n} p\left(y_{\mathrm{LSi}} \mid u_{\mathrm{LSi}}\right)=\prod_{i=1}^{n} \mathrm{I}\left(u_{\mathrm{LSi}} \leq t\right) \mathrm{I}\left(y_{\mathrm{LSi}}=1\right) \\
& +\mathrm{I}\left(u_{\mathrm{LSi}}>t\right) \mathrm{I}\left(y_{\mathrm{LSi}}=2\right)
\end{aligned}
$$

where $\mathrm{I}($.$) was an indicator function with argument as$ defined within parentheses and $t$ was the threshold that defined the two categories of response within the liability framework. The indicator function had a value of 1 if the evaluated expression was true and a value of 0 otherwise. Following a standard Bayesian development, multivariate normal priors were assumed for additive genetic and permanent environmental effects:

$$
\begin{aligned}
& p\left(\mathbf{a} \mid \sigma_{a}^{2}\right) \sim \operatorname{MVN}(\mathbf{0}, \mathbf{A} \otimes \mathbf{G}) \\
& p\left(\mathbf{p} \mid \sigma_{p}^{2}\right) \sim \operatorname{MVN}(\mathbf{0}, \mathbf{I} \otimes \mathbf{P})
\end{aligned}
$$

where $\mathbf{A}$ was the numerator relationship matrix, and $\mathbf{G}$ and $\mathbf{P}$ were the additive genetic and permanent environmental (co)variance matrices, respectively, both with dimensions $3 \times 3$. Three different genetic groups were defined and founders from the same flock of origin were assigned to the same genetic group. Within this context, the numerator relationship matrix was constructed through procedures described by Westell et al. (1988). Flat priors were assumed for systematic effects, as well as for $\mathbf{G}, \mathbf{P}$, and $\mathbf{R}$, with the exception of the $L S$ residual variance, which was fitted to 1 (Sorensen et al., 1995) and the residual variance between BWV and LS, which was assumed null because both traits were defined at different temporal stages. For a given trait $i$, heritability $\left(h_{(i)}^{2}\right)$ was calculated as $h_{(i)}^{2}=\sigma_{a(i)}^{2} /\left(\sigma_{a(i)}^{2}+\sigma_{p(i)}^{2}+\sigma_{e(i)}^{2}\right)$, where $\sigma_{a(i)}^{2}, \quad \sigma_{p(i)}^{2}$ and $\sigma_{e(i)}^{2}$ were the corresponding additive genetic, permanent environmental and residual variances. In a similar way, the coefficient of permanent environment $\left(c_{(i)}^{2}\right)$ was estimated as $c_{(i)}^{2}=\sigma_{p(i)}^{2} /\left(\sigma_{a(i)}^{2}+\sigma_{p(i)}^{2}+\sigma_{e(i)}^{2}\right)$. Correlations between traits $i$ and $j\left(r_{k(i, j)}\right)$ were obtained from $r_{k(i, j)}=\sigma_{k(i, j)} /\left(\sigma_{k(i)} \sigma_{k(j)}\right)$, where $\sigma_{k(i, j)}$ was the covariance between traits $i$ and $j$, and $k \in(a, p, e)$.

In this study, the multivariate model was solved through the Gibbs sampling technique (Gelfand and Smith, 1990), to obtain autocorrelated samples from the joint posterior density and subsequently from the marginal posterior densities of all of the unknowns in the model. It implied an additional step to sample LS liabilities and LW and BWV missing values by data augmentation (Tanner and Wong, 1987). A unique Gibbs sampler chain was launched with 500,000 points and the first 50000 were discarded as burn-in. The effective length of the burn-in period and chain size were calculated following Raftery and Lewis (1992) and Geyer (1992), respectively (Table 2).

\section{Effect of BWV on stillbirths and postnatal mortality}

The frequency of stillbirths and dead lambs in twin births were analysed in five different categories of BWV, (1) $>0.32 \mathrm{~kg}$ and the lamb being the lighter littermate, (2) $>0.32 \mathrm{~kg}$ and the lamb being the heavier littermate, (3) $>0.09 \mathrm{~kg}$ (lighter littermate), (4) $>0.09 \mathrm{~kg}$ (heavier littermate), and (5) $\leq 0.09 \mathrm{~kg}$ (both littermates). Those values were arbitrarily chosen to provide the same number of lambs to each category. This analysis was performed on 1474 twin lambs and losses were grouped as (1) stillbirths (90 lambs), (2) lambs died during the first 7 days of life (75 lambs), and (3) lambs died after the 1st week of life (51 lambs). Frequencies were compared with a $\chi^{2}$ test with 1 degree of freedom.

\section{Results and discussion}

Descriptive statistics

Within-litter birth weight variation showed a skewed distribution with mode 0.19 , median 0.26 , and a slightly greater mean (Figure 1). Nevertheless, its residuals were normally distributed $(P>0.05)$, with a symmetrical density placed around zero (Figure 1). Normality requirements were also adequately met for $\operatorname{LW}(P>0.1)$. Table 1 gives descriptive

Table 2 Length of the burn-in period and effective chain size for each trait analyzed (heritability $\left(\mathrm{h}^{2}\right)$ and permanent environmental coefficient $\left(\mathrm{c}^{2}\right)$ )

\begin{tabular}{lcr}
\hline \hline & Burn-in period & $\begin{array}{r}\text { Effective } \\
\text { chain size }\end{array}$ \\
\hline$h_{\mathrm{BWV}}^{2}$ & 7380 & 31452 \\
$h_{\mathrm{LW}}^{2}$ & 4353 & 79772 \\
$h_{\mathrm{LS}}^{2}$ & 3803 & 29200 \\
$c_{\mathrm{BWV}}^{2}$ & 1001 & 39068 \\
$c_{\mathrm{LW}}^{2}$ & 2001 & 100444 \\
$c_{\mathrm{LS}}^{2}$ & 2652 & 38590 \\
\hline \hline
\end{tabular}



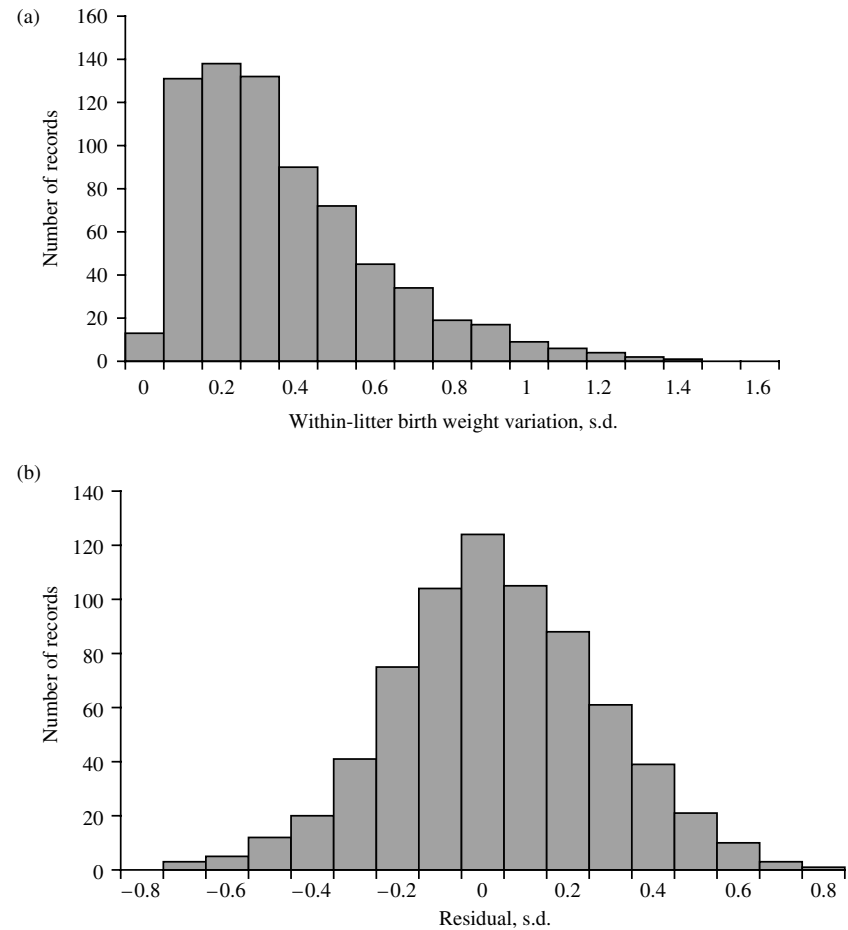

Figure 1 Observed (a) and residual (b) distributions of within-litter birth weight variation.

statistics for the litters included in the genetic analysis (only litters with one or two lambs at birth). Average BWV for twin births was $0.31 \pm 0.01 \mathrm{~kg}$, i.e. an absolute difference of $0.22 \mathrm{~kg}$ between twin littermates. This value is slightly greater than the one reported in newborn piglets (0.25 kg; Damgaard et al., 2003). The average litter weight was $4.89 \pm 0.04 \mathrm{~kg}$, and the difference between single and twin births was between 2 and $2.5 \mathrm{~kg}$, depending on the sex of the progeny (Table 1). Single births were observed in 55\% of the litters, with an average litter size at birth of $1.45 \pm 0.01$ lambs, although this value is slightly underestimated due to the exclusion of 31 triplet and one quadruplet deliveries. These values were within the range reported by El Fadili and Leroy (2001) in Moroccan sheep breeds, and smaller than the averages provided by Freetly and Leymaster (2004) in Dorset, Rambouillet, Suffolk, Finnsheep and Romanov ewes.

\section{Variance components and their ratios}

Genetic variance was detected for BWV (Table 3) whereas permanent environmental variance was almost null. The mode of the marginal posterior distribution of heritability for BWV was low (0.061) although the zero value was out of the higher posterior density region at 95\% (HPD95). This suggests that genetic improvement of BWV by selective breeding could be feasible in the Ripollesa breed. To our knowledge, this is the first estimate of BWV in sheep, and it confirms previous findings in pigs where BWV was reported as being of low heritability (0.08 to 0.10 ; Högberg and Rydhmer, 2000; Damgaard et al., 2003). Genetic selection to homogenise litters at birth may be advantageous for a number of other traits, such as lamb survival (Casellas et al., 2007c), growth of lambs, and the homogeneity of littermates at weaning (Wilson and Réale, 2006).

The heritability for LW was 0.200 , with an HPD95 that ranged between 0.087 and 0.277 . Although the genetic component of LW has not been widely analysed in sheep, our heritability estimate was comparable with those reported by Abdulkhaliq et al. (1989) in Columbia, Suffolk and Targhee breeds, and higher than the heritability observed in Moroccan sheep breeds (El Fadili and Leroy, 2001). Nevertheless, these values were lower than the ones reported in pigs (Sorensen et al., 2000). In a similar way, the mode of the permanent environmental coefficient was 0.199 , with its HPD95 ranging between 0.146 and 0.281 (Table 3).

Litter size is one of the most studied reproductive traits in sheep, and a wide range of heritabilities has been published. Our estimate $(0.141$; Table 3$)$ agrees with the value previously obtained in the same Ripollesa flock (0.131;

Table 3 Variance components, correlations, permanent environment coefficients, and heritabilities for the traits analysed

\begin{tabular}{|c|c|c|c|}
\hline \multirow[b]{2}{*}{ Parameter $^{\dagger}$} & \multirow[b]{2}{*}{ Mode } & \multicolumn{2}{|c|}{$\begin{array}{l}\text { Higher posterior density } \\
\text { region at } 95 \%\end{array}$} \\
\hline & & Lower bound & Higher bound \\
\hline$\sigma_{a(\mathrm{BWV})}^{2}$ & 0.004 & 0.001 & 0.009 \\
\hline$\sigma_{a(\mathrm{LW})}^{2}$ & 0.258 & 0.105 & 0.408 \\
\hline$\sigma_{a(L S)}^{2}$ & 0.187 & 0.069 & 0.327 \\
\hline$\sigma_{p(\mathrm{BWV})}^{2}$ & 0.001 & 0.000 & 0.003 \\
\hline$\sigma_{p(\mathrm{LW})}^{2}$ & 0.265 & 0.188 & 0.365 \\
\hline$\sigma_{p(L S)}^{2}$ & 0.116 & 0.073 & 0.173 \\
\hline$\sigma_{e(B W V)}^{2}$ & 0.063 & 0.056 & 0.071 \\
\hline$\sigma_{e(\mathrm{LW})}^{2}$ & 0.820 & 0.605 & 1.013 \\
\hline$\sigma_{e(\mathrm{LS})}^{2}$ & & Fixed to 1 & \\
\hline$r_{a(\mathrm{BWV}, \mathrm{LW})}$ & 0.151 & -0.708 & 0.930 \\
\hline$r_{a(\mathrm{BWV}, \mathrm{LS})}$ & -0.219 & -0.957 & 0.799 \\
\hline$r_{a(\mathrm{LW}, \mathrm{LS})}$ & -0.320 & -0.668 & 0.274 \\
\hline$r_{p(\mathrm{BWV}, \mathrm{LW})}$ & 0.187 & -0.388 & 0.590 \\
\hline$r_{p(\mathrm{BWV}, \mathrm{LS})}$ & -0.872 & -0.988 & -0.386 \\
\hline$r_{p(\mathrm{LW}, \mathrm{LS})}$ & -0.449 & -0.787 & -0.042 \\
\hline$r_{e(B W V, L W)}$ & 0.010 & -0.072 & 0.090 \\
\hline$r_{\mathrm{e}(\mathrm{BWV}, \mathrm{LS})}$ & & Fixed to 0 & \\
\hline$r_{\mathrm{e}(\mathrm{LW}, \mathrm{LS})}$ & -0.762 & -0.875 & -0.496 \\
\hline$C_{(B W V)}^{2}$ & 0.015 & 0.002 & 0.037 \\
\hline$c_{(\mathrm{LW})}^{2}$ & 0.199 & 0.146 & 0.281 \\
\hline$c_{(L S)}^{2}$ & 0.089 & 0.052 & 0.136 \\
\hline$h_{(\mathrm{BWV})}^{2}$ & 0.061 & 0.009 & 0.127 \\
\hline$h_{(\mathrm{LW})}^{2}$ & 0.200 & 0.087 & 0.277 \\
\hline$h_{(\mathrm{LS})}^{2}$ & 0.141 & 0.057 & 0.226 \\
\hline
\end{tabular}

${ }^{\dagger} \sigma_{a(i)}^{2}$ : additive genetic variance for trait $i ; \sigma_{p(i)}^{2}$ : permanent environmental variance for trait $i ; \sigma_{e(i)}^{2}$ : residual variance for trait $i_{;} r_{a(i, j)}, r_{p(i, j)}, r_{e(i, j)}$ : additive genetic, permanent environmental, and residual correlations between traits $i$ and $j_{i} c_{(i)}^{2}$ : permanent environmental coefficient for trait $i_{;} h_{(i)}^{2}$ : heritability for trait $i$. 
Casellas et al., 2007b), although the HPD95 was smaller for the current heritability ( 0.057 to 0.226$)$. Our heritability estimate was greater than the one observed in Rasa Aragonesa (0.08; Altarriba et al., 1998) and the 0.10 reported by Fogarty (1995), which was an average of estimates obtained in several sheep breeds. Nevertheless, our estimate was clearly lower than the ones reported in Rambouillet and Finnsheep (0.45 and 0.14; Matos et al., 1997), and in two Norwegian sheep breeds, Dala and Spælsau (0.26 and 0.39; Olesen et al., 1994). The permanent environmental coefficient for LS was within the range of previous estimates in Ripollesa sheep (Casellas et al., 2007b).

Genetic, permanent environmental and residual correlations The genetic correlations of BWV with LW and LS were moderately positive $(0.151)$ and negative $(-0.219)$, respectively. Nevertheless, both HPD95 showed a high degree of uncertainty with the null genetic correlation included within the highest probability range (Table 3 ), probably due to the relatively small number of twin litters. Although our estimates only suggested potential genetic correlations, it is interesting to note that they were opposite to the ones observed by Damgaard et al. (2003) in sows and to the negative genetic correlation between BWV and LW reported by Gutiérrez et al. (2006) in mice. As a whole, those results suggested that current selection programmes for LS in the Ripollesa breed (Casellas et al., 2007b) do not genetically increase lamb birth weight heterogeneity. A negative genetic correlation $(-0.320)$ with a HPD95 that ranged between -0.668 and 0.274 was suggested between LW and LS. That value disagrees with the positive genetic correlation described by El Fadili and Leroy (2001) in Moroccan sheep breeds.

The permanent environmental correlation between BWV and LW was small and positive (0.187), with a wide HPD95 ranging between -0.388 and 0.590 (Table 3). It could be related with the small permanent environmental coefficient for BWV. Nevertheless, the permanent environmental effect of LS was negatively correlated with BWV $(-0.872)$ and LW $(-0.449$; Table 3$)$, both correlations

Table 4 Frequencies of stillbirths and died lambs in five different categories of within-litter birth weight variation (BWV)

\begin{tabular}{|c|c|c|c|c|c|c|c|c|}
\hline \multirow[b]{2}{*}{ WLV (kg) } & \multirow[b]{2}{*}{ Littermate } & \multirow[b]{2}{*}{$n$} & \multicolumn{2}{|c|}{ Stillbirths } & \multicolumn{2}{|c|}{$\begin{array}{l}\text { Deaths } \\
\text { (1 to } 7 \\
\text { days) }\end{array}$} & \multicolumn{2}{|c|}{$\begin{array}{c}\text { Deaths } \\
(>8 \\
\text { days })\end{array}$} \\
\hline & & & $n$ & $\%$ & $n$ & $\%$ & $n$ & $\%$ \\
\hline$>0.32$ & Lighter & 285 & 20 & $7.02^{\mathrm{a}}$ & 23 & $8.68^{a}$ & 9 & $3.72^{\mathrm{a}}$ \\
\hline 0.09 to 0.32 & Lighter & 286 & 16 & $5.59^{\mathrm{a}}$ & 19 & $7.04^{\mathrm{a}, \mathrm{b}}$ & 8 & $3.19^{a}$ \\
\hline$\leq 0.09$ & Both & 282 & 19 & $6.74^{\mathrm{a}}$ & 14 & $5.32^{a, b, c}$ & 10 & $4.02^{\mathrm{a}}$ \\
\hline 0.09 to 0.32 & Heavier & 286 & 18 & $6.29^{a}$ & 11 & $4.48^{b, c}$ & 12 & $4.69^{a}$ \\
\hline$>0.32$ & Heavier & 285 & 17 & $5.96^{a}$ & 8 & $2.99^{c}$ & 12 & $4.62^{\mathrm{a}}$ \\
\hline Overall & & 1424 & 90 & 6.32 & 75 & 5.62 & 51 & 4.05 \\
\hline
\end{tabular}

$\mathrm{a}, \mathrm{b}, \mathrm{c}$ Estimates with the same superscript do not differ significantly $(P>0.05)$. with a HPD95 ranging far away from the null correlation. Within this context, highly prolific ewes could generate lighter and more homogeneous litters, although the correlation between LS and BWV must be corroborated in future studies.

The residual correlation was null between BWV and LW (Table 3). To our knowledge, no comparable results are available in sheep, whereas BWV and average birth weight showed a significant negative residual correlation in pigs (Damgaard et al., 2003). Litter weight and LS residuals were negatively correlated in the Ripollesa ewe $(-0.762)$, with a moderate HPD95 ranging between -0.875 and -0.496 (Table 3). The inclusion of birth type as an additional systematic effect in the operational model of LW accounts for the increase due to birth type (Freetly and Leymaster, 2004) and, interestingly, the residual correlation implies an additional negative relationship between LW and LS.

\section{Influences of BWV on lamb survivability}

There is general agreement that high BWV results in decreased survival in newborn pigs (Roehe and Kalm, 2000; Milligan et al., 2001), although it has not been studied in lambs. The survivability of 1424 Ripollesa lambs was studied, showing an average stillbirth incidence of $6.32 \%$. Seventy-five deaths occurred during the 1 st week of life $(5.62 \%)$ and 51 lambs died after the 1st week $(4.05 \%)$ (Table 4). These percentages were similar to those reported by Binns et al. (2002) and Casellas et al. (2007c). Frequencies were compared with a $\chi^{2}$ test with 1 degree of freedom. Stillbirths were not influenced by BWV $(P>0.05)$, as was previously reported by Leenhouwers et al. (1999) and Damgaard et al. (2003) in swine. On the other hand, early postnatal mortality varied with BWV $(P<0.05)$, with an opposed effect on heavier and lighter littermates, and lamb mortality after the 1st week of life did not show significant differences between BWV categories. Extreme values of BWV significantly $(P<0.05)$ increased $(8.68 \%)$ and reduced $(2.99 \%)$ early lamb mortality for lighter and heavier littermates, respectively. The same trend was observed for intermediate BWV $(7.04 \%$ and $4.48 \%$ ) although the difference was not significant $(P>0.05)$. To our best knowledge, these are the first results showing a within-litter divergent effect of BWV on lamb survival, a new endeavor to highlight the key influence of foetal nutrition on the postnatal period (Wu et al., 2006). It agrees with the previous research of Mellor (1983) and Ocak et al. (2005), which related foetal nutrition and growth with newborn lamb survival.

\section{Conclusions}

Within-litter birth weight variation in Ripollesa sheep showed a low heritability (0.061), clearly lower than the ones obtained for litter weight $(0.200)$ and litter size (0.141). Nevertheless, genetic selection for birth weight homogeneity seems feasible, and selection by ewes' ability to give homogeneous litters may be advantageous for a number of productive traits, such as lamb survival, as well 
as for homogenising growth and weaning age in twin births. Within this context, BWV significantly influenced early postnatal lamb mortality, with a divergent effect on heavier and lighter littermates. Within-litter birth weight variation could be genetically correlated with litter weight $(0.151)$ and litter size $(-0.219)$, but those estimates suffered from a high degree of uncertainty. This study emphasises the complexity of the genetic architecture of birth weight, a key trait in lamb survival and production.

\section{Acknowledgements}

Research supported by a contract with the Departament d'Agricultura, Ramaderia i Pesca de la Generalitat de Catalunya (Spain) and a Universitat Autònoma de Barcelona (Bellaterra, Spain) fellowship granted to J. Casellas. The authors appreciate the assistance of A. Ferret, X. Such, R. Costa and the crew of the S1GCE (Servei de Granges i Camps Experimentals de la UAB, Bellaterra, Spain) for feeding and care of the animals. We thank L. Varona for contributing the software. The English revision of N. Aldam is also acknowledged.

\section{References}

Abdulkhaliq AM, Harvey WR and Parker CF 1989. Genetic parameters for ewe productivity traits in the Columbia, Suffolk and Targhee breeds. Journal of Animal Science 67, 3250-3257.

Altarriba J, Varona L, García-Cortés LA and Moreno C 1998. Bayesian inference of variance components for litter size in Rasa Aragonesa sheep. Journal of Animal Science 76, 23-28.

Bhuiyan AKFH and Curran MK 1993. Genetic trends of prolificacy and litter size in Romney Marsh sheep. Small Ruminant Research 12, 315-320.

Binns SH, Cox IJ, Rizvi S and Green LE 2002. Risk factors for lamb mortality on UK sheep farms. Preventive Veterinary Medicine 52, 287-303.

Casellas J, Caja G, Ferret A and Piedrafita J 2007a. Analysis of litter size and days to lambing in the Ripollesa ewe. I. Comparison of models with linear and threshold approaches. Journal of Animal Science 85, 618-624.

Casellas J, Caja G, Ferret A and Piedrafita J 2007b. Analysis of litter size and days to lambing in the Ripollesa ewe. II. Estimation of variance components and response to phenotypic selection on litter size. Journal of Animal Science 85, 625-631.

Casellas J, Caja G, Such X and Piedrafita J 2007c. Survival analysis from birth to slaughter of Ripollesa lambs under semi-intensive management. Journal of Animal Science 85, 512-517.

Christley RM, Morgan KL, Parkin TDH and French NP 2003. Factors related to the risk of neonatal mortality, birth weight and serum immunoglobulin concentration in lambs in the UK. Preventive Veterinary Medicine 57, 209-226.

Damgaard LH, Rydhmer L, Løvendahl P and Grandinson K 2003. Genetic parameters for within-litter variation in piglet birth weight and change in withinlitter variation during suckling. Journal of Animal Science 81, 604-610.

Dwyer CM and Morgan CA 2006. Maintenance of body temperature in the neonatal lamb: effects of breed, birth weight, and litter size. Journal of Animal Science 84, 1093-1101.

El Fadili M and Leroy PL 2001. Estimation of additive and non-additive genetic parameters for reproduction, growth and survival traits in crosses between the Moroccan D'man and Timahdite sheep breeds. Journal of Animal Breeding and Genetics 118, 341-353.

Fogarty NM 1995. Genetic parameters for live weight, fat and muscle measurements, wool production and reproduction in sheep: A review. Animal Breeding Abstracts 63, 101-143.

Freetly HC and Leymaster KA 2004. Relationship between litter birth weight and litter size in six breeds of sheep. Journal of Animal Science 82, 612-618.
Gama LT, Dickerson GE, Young LD and Leymaster KA 1991. Effects of breed, heterosis, age of dam, litter size, and birth weight on lamb mortality. Journal of Animal Science 69, 2727-2743.

Garreau H, Bolet G, Hurtaud J, Larzul C, Robert-Granié C, Ros M, Saleil G, SanCristobal M and Bodin L 2004. Homogeneización genética de un character. Resultados preliminaries de una selección canalizante sobre el peso al nacimiento de los gazapos. ITEA Producción Animal 100, 172-178.

Gelfand A and Smith AFM 1990. Sampling based approaches to calculating marginal densities. Journal of the American Statistical Association 85, 398-409.

Geyer CJ 1992. Practical Markov chain Monte Carlo. Statistical Science 7, 473-483.

Gianola D and Fernando RL 1986. Bayesian methods in animal breeding theory. Journal of Animal Science 63, 217-244.

Guillaumet J and Caja G 2001. La raza ovina Ripollesa: Características productivas y organización de la mejora de la raza. Ganadería 7, 47-54.

Gutiérrez JP, Nieto B, Piqueras P, Ibáñez N and Salgado C 2006. Genetic parameters for canalisation analysis of litter size and litter weight traits at birth in mice. Genetics, Selection, Evolution 38, 445-462.

Henderson CR 1973. Sire evaluation and genetic trends. In Proceedings of animal breeding and genetics symposium in honour of Dr JL Lush, pp. 10-41. American Society of Animal Science, American Dairy Science Association, Champaign, IL.

Högberg A and Rydhmer $L$ 2000. A genetic study of piglet growth and survival. Acta Agricola Scandinavia (Sect. A) 50, 300-303.

Knol EF 2001. Genetic aspects of piglet survival. PhD, Wageningen Universitet, The Netherlands.

Leenhouwers Jl, van der Lende T and Knol EF 1999. Analysis of stillbirths in different lines of pigs. Livestock Production Science 57, 243-253.

Matos CAP, Thomas DL, Gianola D, Tempelman RJ and Young LD 1997. Genetic analysis of discrete reproductive traits in sheep using linear and nonlinear models: I. Estimation of genetic parameters. Journal of Animal Science 75, 76-87.

Mellor DJ 1983. Nutritional and placental determinants of fetal growth rate in sheep and consequences for the newborn lamb. The British Veterinary Journal 139, 307-324.

Milán MJ, Arnalte E and Caja G 2003. Economic profitability and typology of Ripollesa breed sheep farms in Spain. Small Ruminant Research 49, 97-105.

Milligan BN, Fraser D and Kramer DL 2001. Birth weight variation in the domestic pig: effects on offspring survival, weight gain and suckling behaviour. Applied Animal Behaviour Science 73, 179-191.

Ocak N, Cam MA and Kuran M 2005. The effect of high dietary protein levels during late gestation on colostrums yield and lamb survival rate in singletonbearing ewes. Small Ruminant Research 56, 89-93.

Olesen I, Pérez-Enciso M, Gianola D and Thomas DL 1994. A comparison of normal and nonnormal mixed models for number of lambs born in Norwegian sheep. Journal of Animal Science 72, 1166-1173.

Raftery AE and Lewis SM 1992. How many iterations in the Gibbs sampler? Bayesian Statistics IV (ed. JM Bernardo, JO Berger, AP Dawid and AFM Smith), Oxford University Press, Oxford, UK, pp. 763.

Roehe R and Kalm E 2000. Estimation of genetic and environmental risk factors associated with pre-weaning mortality in piglets using generalised linear mixed models. Animal Science 70, 227-240.

Sánchez Belda A and Sánchez Trujillano MC 1986. Razas Ovinas Españolas, Publicaciones de Extensión Agraria, MAPA, Madrid, Spain

Shapiro SS and Wilk MB 1965. An analysis of variance test for normality (complete samples). Biometrika 52, 591-611.

Sorensen D, Andersen S, Gianola D and Korsgaard I 1995. Bayesian inference in threshold models using Gibbs sampling. Genetics, Selection, Evolution 27, 229-249.

Sorensen D, Vernersen A and Andersen S 2000. Bayesian analysis of response to selection: A case study using litter size in Danish Yorkshire pigs. Genetics 156, 283-295.

Sorensen D, Wang CS, Jensen J and Gianola D 1994. Bayesian analysis of genetic change due to selection using Gibbs sampling. Genetics, Selection, Evolution 26, 333-360. 


\section{Casellas, Caja and Piedrafita}

Tanner MA and Wong WH 1987. The calculation of posterior distributions by data augmentation. Journal of the American Statistical Association 82, 528-550.

Torre C 1991. Características productivas de ovejas de raza Ripollesa en pureza y en cruzamiento con moruecos de raza Merino Precoz y Fleischschaf. PhD, University Autònoma of Barcelona, Spain.

Van Engelen MAJ, Nielsen MK and Ribeiro EL de A 1995. Differences in pup birth weight, pup variability within litters, and dam weight of mice selected for alternative criteria to increase litter size. Journal of Animal Science 73, 1948-1953.

Van Tassell CP, Van Vleck LD and Gregory KE 1998. Bayesian analysis of twinning and ovulation rates using a multiple-trait threshold model and Gibbs sampling. Journal of Animal Science 76, 2048-2061.
Wang CS, Gianola D, Sorensen D and Jensen J 1994. Response to selection for litter size in Danish Landrace pigs: a Bayesian analysis. Theoretical and Applied Genetics 88, 220-230.

Westell RA, Quaas RL and Van Vleck LD 1988. Genetic groups in an animal model. Journal of Dairy Science 71, 1310-1318.

Wilson AJ and Réale D 2006. Ontogeny of additive and maternal genetic effects: lessons from domestic mammals. The American Naturalist 167, E23-E38.

Wright S 1934. An analysis of variability in number of digits in an inbred strain of Guinea pigs. Genetics 19, 506-536.

Wu G, Bazer FW, Wallace JM and Spencer TE 2006. Board-invited review: Intrauterine growth retardation: Implications for the animal sciences. Journal of Animal Science 84, 2316-2337. 